\title{
APROPIACIÓN TRANSGRESIVA Y MULTIMODALIDAD EN LA INVESTIGACIÓN ACADÉMICA: \\ propuestas de escrilectura
}

Máximo Daniel Lamela Adó

Mariana Mussetta

\section{Resumen}

Las nociones de apropiación transgresiva y multimodalidad en la investigación académica conllevan necesariamente un cuestionamiento de las formas canónicas fosilizadas de leer y escribir en la academia, y proponen en cambio procedimientos que visibilicen el proceso y la persona atravesada por ese proceso, así como el contexto semiótico y sensible que lo involucra. Postulan que se logre la incorporación de otros lenguajes y recursos, para así romper con la vara positivista con la que aún hoy se mide la calidad de la producción académica en las humanidades. Por otra parte, plantean que tales procedimientos se valgan de una fuerza usurpadora que pueda dar lugar a una pulsión creadora. Se trata de descontextualizar, desnaturalizar, deconstruir, dislocar, para permitir que se produzcan nuevas asociaciones, nuevos inventos. Se aspira a una escrilectura académica transgénero, contra-academicista, y multirrecursos: la confección de una trama que piense el currículo desde la perspectiva de una devoración positiva que haga de la investigación académica un ambiente de inmanencia.

Palabras clave: apropiación transgresiva; multimodalidad; escrilectura; escrituras académicas disidentes; traducción-usurpadora

\section{TRANSGRESSIVE APPROPRIATION AND MULTIMODALITY IN ACADEMIC RESEARCH: proposals of writereading}

\section{Abstract}

The notions of transgressive appropriation and multimodality in academic research necessarily entail a questioning of the fossilized canonical forms of reading and writing in the academy, and propose instead procedures that make both the process and the person going through it visible, as well as the semiotic and sensitive context that it involves. They postulate that the incorporation of other languages and resources be achieved, in order to break with the positivist yardstick with which the quality of academic production in the humanities is measured even today. On the other hand, they propose that such procedures use a usurping force that can give rise to a creative impulse. It is a matter of decontextualising, denaturalising, deconstructing, dislocating, in order to allow new associations, new inventions to be produced. We aspire to a transgender, counter-academicist and multi-source academic writereading: the creation of a fabric that views the curriculum from the perspective of a positive devoration that makes academic research an immanence environment.

Keywords: transgressive appropriation; multimodality; writereading; dissident academic writing; translationusurpation 


\section{APROPRIAÇÃO TRANSGRESSIVA E MULTIMODALIDADE NA PESQUISA ACADÊMICA: propostas de escrileitura}

\section{Resumo}

As noções de apropriação transgressiva e multimodalidade na pesquisa acadêmica implicam necessariamente um questionamento das formas canônicas fossilizadas de ler e escrever na academia e, em vez disso, propõe procedimentos que tornam visível o processo e a pessoa que por ele é atravessada, assim como o contexto semiótico e sensível que ele envolve. Postulam a incorporação de outras linguagens e recursos, a fim de romper com a vara positivista com a qual ainda hoje se mede a qualidade da produção acadêmica nas humanidades. Por outro lado, propõem que tais procedimentos se utilizem de uma força usurpadora que pode dar origem a uma pulsão criadora. Trata-se de descontextualizar, desnaturalizar, desconstruir, deslocar, para permitir a produção de novas associações, novas invenções. Aspira-se por uma escrita acadêmica transgênero, contra-academicista e multirecursos: a criação de uma trama que pense o currículo a partir da perspectiva de uma devoração positiva que faça da pesquisa acadêmica um ambiente de imanência.

Palavras-chave: apropriação transgressiva; multimodalidade; escrileitura; escritas acadêmicas dissidentes; tradução-usurpadora

[...] Escribo este texto en primera persona del singular y en el femenino, aún cuando seamos dos para escribirlo. Lo que me interesa es el efecto de la potencia de una voz disidente. Esta voz que, por sí, ya se presenta transgresiva. Voz que pone en evidencia que lo neutro es una invención que ya no le sirve a la academia, voz de la que quiero apropiarme. El problema prefigurado en el texto es justamente ese, el del modo de escribir como una usurpación, sin límites, para hacer de la academia un espacio que comporte la potencia del contagio en el fecundo atravesamiento de campos diversos. Una vOz que también llame la atención hacia el papel, o pantalla, o écran, o display que soporta mi investigación. Un soporte que no encubra el proceso; que deje que la vida aparezca en las tramas de una proliferación múltiple para que el pensar pueda ser un encuentro con signos y un acto de sensibilidad. Del mismo modo que se puede decir que se piensa en el arte y en las formas por ella producidas. Una voz que al decir "yo" se exprese como una multitud desde una zona de fecundidad y multiplicación. Una voz que usurpe otras voces para proliferar sus coordenadas de alegría y pulsión creadora. Para hacer de la apropiación una gesta transgresiva hacia nuevos modos de leer lo ya conocido. Con eso: 1) proclama una lectura de invención; la lectura que en pliegue se torna reescritura y que, por eso, no es más que una operación traductora; 2) muestra que la invención, para que sea invención, carece de variación, o sea, las maneras de expresar se llenan/saturan/cargan de contenido y necesitan ser una potencia de diferenciación; para eso está la multimodalidad como una puesta en juego de esa trama. Una trama que piensa el currículo desde la perspectiva de una devoración positiva que hace de la investigación académica un ambiente de inmanencia. 


\section{REESCRIBIR, UN IMPULSO USURPADOR}

El concepto de texto definitivo no corresponde sino a la religión

(BORGES, 1984, p. 239)

El gusto por la lectura puede transmutar a la lectora en una usurpadora de imágenes. Imágenes visuales e imágenes de pensamiento. El pensamiento como un estilo creador que hace de la repetición, diferencia; el pensamiento que, para existir, no se encierra en lo ya conocido, sino que le captura el movimiento. Como en una práctica deportiva que se vale de las fuerzas de los vientos y las mareas, este pensamiento busca equilibrio y potencia al insertarse en una ola preexistente. Por esa vía la lectora busca colocarse en órbita junto a las fuerzas motrices de una escritura. Recurro a Paul Valéry (1991) para ponderar que el gusto por la lectura se equipara a una tentación. Evoco una especie de lectora mefistofélica que en acto de lectura se pone en búsqueda de algo que podría tentarla a una voluntad de composición. Voluntad que, tempranamente, la conduzca a la fabricación de una máquina de escritura. Se trata de la tentación de no embriagarse en la lectura y estar atenta al acto para aceptar de ella solamente las imágenes que se procuran. Un proceso de devoración que supone el escribir como un trabajo de traducción (VALÉRY, 1956); un trabajo que, por poner la lectura en pliegue, asume la escritura como reescritura.

La reescritura pasa a ser resultado del impulso usurpador de una lectora mefistofélica. Infiel e insumisa, esta lectora captura cierta ánima de lo leído. Encarna una plagiotropista desvergonzada al hacer de la lectura un gesto oblicuo que produce una suerte de canto paralelo que derive en reescritura. Sería un acontecimiento de usurpación maquínica que hace de la lectora una productora activa. Un modo de leer que implica, a su propio gusto, la posibilidad de una actitud no reverencial frente a la tradición; actitud que implica expropiación, reversión, desjerarquización (CAMPOS, 2013a), o sea, traducción o escritura como apropiación transgresiva. Hay que subrayar la formulación radical que Paul Valéry (1956) establece para el acto traductor. Se trata de borrar estratégicamente una supuesta diferencia categorial entre escritura y traducción (CAMPOS, 2013b). En la literatura filosófica o filosofía literaria de Paul Valéry, escribir, sea lo que sea, es traducir, siempre que ese acto sea un acto de reflexión. En ese sentido se concibe a la literatura como una permanente operación traductora, es decir, se relativiza la categoría de originalidad y se coloca en escena la intertextualidad generalizada (CAMPOS, 2013b). Con eso Valéry hace prevalecer la idea de una lectora insurrecta. La traductora pasa a ser una transcreadora (CAMPOS, 2013a), una vez que opera una apropiación de la historicidad del texto original para, con esa apropiación, darle la composición de una tradición viva. Como una poeta, esta escritoratraductora, esta escrilectora (CORAZZA, 2008) necesita redibujar o volver a trazar algo que estaba apagado.

La insumisión a la tradición no es negarla, sino perspectivarla en su nuevo contexto. Con el texto del presente problematizarla y, con eso, ponerla en crisis insertándole una ruptura. La reescritura se convierte en una lectura traductora, no solamente en la medida que el texto persigue una convergencia de textos posibles, sino también en la medida en que esa relación con un texto ajeno, que se vale de la reescritura, se cruza en una relación de propiedad. Así la escritora [y la investigadora académica] "[...] enfrenta de un modo específico la contradicción entre escritura social y apropiación privada que aparece muy visiblemente en las cuestiones que suscitan el plagio, la cita, la parodia, la traducción, el pastiche, el apócrifo" (PIGLIA, 2017, p. 63). Se trata de asumir que, en lectura y escritura, pero también en cultura e historia, lo que se suele tener es una miríada de textos contaminados de otros textos. Pero, también, y eso no es menor, de la vida 
e historia de aquellas y aquellos que los componen. De un texto a otro no hay vacíos, sino precisamente cierta determinación de los modos de leer, es decir, las relaciones sociales que les dan razones a esos modos.

Contacto y contagio, así se procesa la escritura como reescritura. Contagio de textos. Contagios de vida. Por lo tanto, la reescritura suele ser la escritura misma, su versión prontamente asumida como no original, como el desplazamiento del lenguaje que hace de la traducción un hecho brutal, una transcreación diabólica y que no pide permiso. De Paul Valéry al cineasta norteamericano Quentin Tarantino, mucho se ha transformado en el ecosistema de intercambios simbólicos, aunque sus prácticas se asemejan y están implicadas en un desplazamiento. Desplazamiento en el espacio y en el tiempo, desplazamientos geográficos y culturales. Desplazamientos que hacen de los procedimientos de creación un laboratorio o máquina de descontextualización al modo de una fabricación creadora de sus antecesores y precursores. Lo que se crea es una lógica del contagio, donde el modo de leer recrea nuevas territorializaciones y devoraciones. La poética citacional que vemos en Kill Bill ${ }^{\wedge}$ es una usurpación al mismo modo que lo es el Mon Faust (Ébauches) de Paul Valéry. La reescritura como una suerte de acción traductora es la puesta en práctica de la técnica de Pierre Menard ${ }^{2}$, este autor inventado por Borges que mucho se parece a Valéry y que se admite como el autor del Quijote utilizando la técnica que denomina de anacronismo deliberado y atribuciones erróneas (BORGES, 1984, p. 450). Pierre Menard pone en escena el contexto del no contexto, espécimen de práctica en que el significado se vuelve flexible, pues alejado de su circunstancia original se renueva en el enclave de otros marcos lectores.

\section{Volver visible quien escribe}

La crítica, nos dice Piglia (2017), es la forma moderna de la autobiografía. La frase de Piglia no es más que una relectura fagocitaria [¿o sería una reescritura?] de una frase de Paul Valéry (2002) que se puede leer en el texto de la conferencia Poésie et pensée abstraite, pronunciada en The Zaharoff Lecture en 1939. Nos dice Valéry: "En la verdad, no existe teoría que no sea un fragmento cuidadosamente preparado de alguna autobiografía" (VALÉRY, 2002, p. 1320, nuestra traducción) $)^{3}$. El sujeto de la crítica tiene como máscara el método, a veces el sujeto es el método; pensemos en Descartes y el método cartesiano. Una manera perspectivista de sacarle la máscara a esa crítica y, de algún modo, hacer que aparezca quien escribe sería valerse de las preguntas: ¿por qué?, ¿desde dónde?, ¿’en qué circunstancia? Se escribe. ¿Desde cuál concepción? La crítica habla de eso. ¿Nosotras, como investigadoras académicas qué hacemos? ¿Cuál es el lugar de la verdad en la crítica y en la investigación? Quizás, un modo de volver visible el proceso de una escritura es asumir el acto de escribir como una ficción que permite trabajar la verdad en el discurso. La crítica es también un modo de ficcionalizar el yo que escribe. "Alguien escribe su vida cuando cree escribir sus lecturas" (PIGLIA, 2017, p. 13). La crítica, y aquí acerco la investigación académica a la crítica, admite o piensa admitir que escribe desde una posición concreta y un lugar preciso y, por ese motivo, al hacer crítica constituyendo teoría está enmascarando una producción autobiográfica que a su vez es ideológica, teórica, política y cultural.

\footnotetext{
1 “Kill Bill” es el título de una película estadounidense dirigida y escrita por Quentin Tarantino. La película fue estrenada en dos volúmenes, primera parte en 2003 y segunda parte en 2004. Las citas cinematográficas son frecuentes y numerosas, donde se crea una relación intensa con cierta tradición cinematográfica.

${ }^{2}$ Pierre Menard es un personaje del cuento "Pierre Menard, autor del Quijote". Un cuento de Borges publicado en Ficciones, libro de cuentos publicado en 1941.

3 "En vérité, il n'est pas de théorie qui ne soit un fragment, soigneusement préparé, de quelque autobiographie."
}

Revista Teias v. 21 • n. 63• out./dez. 2020 • Seção Temática Docência, currículo, didática, aula: fantástico arquivo político da diferença 
La ficción trabaja con la verdad para construir un discurso que no es ni verdadero ni falso. Que no pretende ser ni verdadero ni falso. Y en ese matiz indecidible entre la verdad y la falsedad se juega todo el efecto de la ficción. Mientras que la crítica trabaja con la verdad de otro modo. Trabaja con criterios de verdad más firmes y a la vez más nítidamente ideológicos. Todo el trabajo de la crítica, se podría decir, consiste en borrar la incertidumbre que define a la ficción. El crítico trata de hacer oír su voz como una voz verdadera (PIGLIA, 2017, p. 13).

Aun, si admito que la teoría, como un trabajo de la investigación y de la crítica, no es un espejo de la realidad, la sabiduría del mundo y de la vida, admito, también, que no es una verdad descubierta, sino una escritura en pliegue, pliegue sobre pliegue. Puedo decir, como lo dijo Valéry, que hacer teoría es imponer a esa escritura un fragmento autobiográfico y, con eso, señalar que la teoría está directamente implicada en la producción de aquello que describe y explica. Cuando describe un objeto, lo inventa. Por ese motivo una escritura académica que no se recusa como ficcional pone en tensión una supuesta ilusión de objetividad y conlleva, en su práctica, la ruptura de la trama de una cierta concepción de género: ficción y no ficción. Hace deslizar las fronteras bien definidas contaminando, por injerto tal vez, los discursos unívocos, aquellos supuestamente neutrales y universales. Quizás, poder hacer visible quien escribe empiece por no borrar el proceso investigativo y de montaje de una escritura.

Fuerzas ficticias y modos de leer

En un texto de Crítica y ficción ${ }^{4}$ (PIGLIA, 2017), Roberto P. Guareschi y Jorge Halperín le hacen una pregunta a Ricardo Piglia, pregunta que resumo aquí para nuestro interés: ¿Cómo nacen y crecen las ideas en el pensamiento colectivo? Piglia utiliza un extracto de Valéry que consta en el Prólogo de Lettres persanes de Montesquieu para afirmar que tal vez el centro de la reflexión política de un escritor (y aquí pensamos en nuestras investigaciones) es tratar de trabajar con las fuerzas ficticias, para escrutar, tal vez, las estructuras de esa fuerza. El extracto de Valéry que está asociado con el pensamiento de Gramsci es el siguiente: "La era del orden es el imperio de las ficciones, pues no hay poder capaz de fundar el orden con la sola represión de los cuerpos con los cuerpos. Se necesitan fuerzas ficticias" (VALÉRY apud PIGLIA, 2017, p. 33).

El trasfondo de esto es que la sociedad es vista como una trama de relatos, un conjunto de historias y ficciones que circulan entre la gente. En este sentido Piglia observa que hay un circuito personal, una ficción particular, y también hay, no podría ser diferente, una voz pública, un movimiento social de la historia. En ese vaivén de relatos se crea un flujo de lectores que incorporan ficciones que nacen y crecen en el pensamiento colectivo. De esta manera, asumimos que vivimos entre ficciones, o sea, entre tramas que circulan.

A partir de eso me interesa hacer una especie de inventario de ficciones, siempre bastante microscópico o miniaturizado. Ese inventario procura tratar la noción de autoficción que contamina la producción teórica académica, es decir, la producción teórica producida en nuestras investigaciones. Elijo el término autoficción a autobiografía, pues entiendo la autoficción como un efecto paródico de las retóricas autobiográficas y, de esa manera también subrayo la idea de ficción del yo. Sin embargo, no entiendo la autoficción como un género, sino como una práctica bastante imprecisa desde el plan de creación hasta el plan de recepción (PRIETO, 2019). Una práctica que, me parece, ayuda a inculcar o a contagiar las voces de quien escribe a un cierto sistema de discursos o consensos de estas tramas que circulan. Recordemos "Kafka y sus

${ }^{4}$ Una trama de relatos entrevista de Clarín, 27 de mayo de 1984. 
precursores" de Borges (Otras Inquisiciones): "El hecho es que cada escritor crea a sus precursores. Su labor modifica nuestra concepción del pasado, como ha de modificar el futuro" (BORGES, 1984, p. 710). En la concepción de Borges, cada escritor, a partir de la lectura, inserta una variedad creativa en su trabajo, por lo que no sigue una especie de sumisión, sino que inventa un precursor y al hacerlo lo modifica, estableciendo otro mundo de lectores sobre esa lectura con la que trabajó. Por eso no se puede definir un género, porque cuando se define ya no existe como tal, es siempre una obra asincrónica, a posteriori.

Lo que digo es que mi preocupación no es escribir ficción en la academia, porque para escribir ficción no es necesario estar en la academia. Pero me interesa una estrategia de redireccionar los discursos. Como dije antes, al insertar algo diferente en cierto sistema, éste se altera. De esta manera se trabaja, no para el consenso - en el sentido de insertar ficción en la academia para, digamos, mejorar el discurso de la academia - sino para el fortalecimiento de la diferencia y la reorientación e inserción de nuevas voces y formas de hablar.

En ese sentido, me gusta cierta forma de la escritura que tensa las fronteras de los géneros desarticulando los códigos de lectura: pienso en "Tlön, Uqbar, Orbis Tertius" (BORGES, 1984). Este texto es una referencia desde hace mucho tiempo, y siempre tengo la sensación de no haberlo leído completamente todavía. Cuando hablo de Tlön, pienso también en los precursores que al escribir Tlön Borges crea y así revitaliza las formas de leerlos; no me refiero sólo a los escritores con los que dialoga: Macedonio Fernández, Russell, Valéry, sino a la forma de leer ficciones, de leer cuentos. Recordemos que Tlön es el primer cuento de Ficciones, libro de Borges publicado en 1941.

Ricardo Piglia llama a este tipo de texto ficción conceptual. Esta idea ya estaría en el conjunto de textos que forman el Monsieur Teste de Valéry (1946), como literatura no empirica. Siempre estoy leyendo un texto con otro, a veces es el anacronismo y la lectura fuera de contexto lo que opera. Si leo a Borges antes de leer a Valéry, ¿cuál idea es la que viene antes?

También aprovecho el concepto de ficción de Juan José Saer (2014, p. 9); la ficción para Saer puede ser entendida como una antropología especulativa. Comienza el texto titulado "El concepto de ficción" afirmando que nunca sabremos cómo fue James Joyce, cuyos biógrafos tomarán matices de cartas y entrevistas, y que este método recuerda el testimonio del "[...] hombre que vio al hombre que vio al oso".

Lo que Saer parece destacar es que cualquier objetividad, cuando pasa al campo interpretativo, titubea. Y así hace que el problema del objeto, en este caso la biografía de Joyce, contamine la metodología del biógrafo. El sujeto es el método, dije antes.

Así pues, es importante señalar que la veracidad como requisito de la biografía (atributo científico) no es más que un supuesto retórico de un género literario. Por eso dice que podemos afirmar que la verdad no es necesariamente lo contrario de la ficción, y cuando elegimos la ficción no lo hacemos con el turbio propósito de tergiversar la verdad, sino asumir cierta incapacidad para probar su eficacia.

Lo que quiero es resaltar el carácter complejo que implica el tratamiento limitado a lo verificable. La ficción, de alguna manera, da un salto a lo inverificable, y con este salto se multiplican, hasta el infinito, las posibilidades de tratamiento. No se trata de dar la espalda a una realidad objetiva, "muy por el contrario", nos dice Saer (2014, p. 11), entramos en su turbulencia despreciando la actitud ingenua que consiste en pretender saber, por anticipación, cómo se hace esta realidad. De esta manera la ficción no es una reivindicación de lo falso, sino señalar que al imbricar lo empírico con lo imaginario se aumenta la credibilidad de lo que hay que entender, no como verdad, sino como ficción. La ficción como un tratamiento específico del mundo y este 
tratamiento es inseparable de lo que se trata. La ficción como la forma más apropiada de tratar las relaciones complejas.

De esta manera se buscan nuevas formas de expresión y contenidos, que derivan de recorridos intensivos y trayectorias extensivas de las producciones que se realizan, desde hace algunos años, en el campo educativo [ y en las artes y literaturas]; luchas contra la sequedad de los corazones, la apatía en las relaciones y la dureza de los códigos; inspiraciones aportadas por filósofos, escritores, educadores del Pensamiento de la Diferencia, que participan en un gesto colectivo, cuyo lema es la simple palabra de Nietzsche, aunque dotado de infinita potencia: "Una nueva forma de sentir, una nueva forma de pensar." (CORAZZA, 2013, p. 34-35, nuestra traducción)

\section{EL DESAFÍO DE LAS ESCRITURAS ACADÉMICAS MULTIMODALES}

Un enfoque multimodal de la publicación cientifica es una oportunidad para superar las limitaciones inherentes a los modos de comunicación y representación preferidos que se utilizan en las revistas científicas convencionales, [...] y una oportunidad para incluir una gama más amplia de recursos semióticos en un artículo de investigación

(BLANCA, 2014, p. 28, nuestra traducción) ${ }^{5}$.

Aquella servilleta de papel donde cuajó la idea para el próximo artículo. Borroneada, con el pulso entusiasmado de novedad. Con iniciales de autoras a los costados. Con palabras tachadas de la idea anterior a la elegida, pero sin la cual la elegida no podría existir. Los cuadros, las flechas, los signos de admiración o pregunta al margen de la hoja. Los infinitos globos con comentarios en los archivos de texto. La textura virtual, la corporeidad digital de la tipografía característica de aquel artículo finalmente conseguido luego de mucha búsqueda. El matiz amarillento de la función marcador que varía según la calidad del escaneado. Las marcas ajenas y anónimas en los textos que circulan y de los que me alimento. Ricos paratextos apócrifos. Las imágenes, los colores, la resonancia del comentario oportuno que me hizo pensar. Los interminables mensajes entre pares intercambiando hipervínculos, nombres, sugerencias de lectura, consejos a becarios, relecturas y revisiones, retroalimentación de retroalimentación. Las conexiones con lecturas que parecían olvidadas, las asociaciones personales construidas con años de lectura, relectura, escritura, reescritura, relecturareescritura. Cortar, copiar, pegar, hacer y deshacer. Ver, pensar, tipear, googlear, buscar archivo, buscar palabra. Búsqueda avanzada. Dendritas conceptuales navegando el blanco de la página con el cursor.

Hasta que llega el momento de limpiar el borrador para someter el ¡manuscrito! a publicación. Hacerlo pulcro, aséptico. Times New Roman 12. Justificado. Estilo APA. Impersonalidad absoluta. Hacer pasar todo ese torbellino por el filtro de las normas requeridas. Y lo que no se ajusta, queda fuera. Los cuadros, las flechas, los colores, las conexiones, la vida misma. Una ilusión de producto sin proceso previo. Sólo quedan palabras, y no cualquier palabra. El corset de la voz pasiva y únicamente ciertos conectores admitidos. Nada de adjetivos calificativos. Número máximo de caracteres. Autoadiestramiento.

\footnotetext{
5 A multimodal approach to scientific publishing is an opportunity to overcome the inherent limitations of the preferred modes of communication and representation used in conventional, printed or online, scientific journals [...] and an opportunity to include a wider range of semiotic resources in a research article.
} 
¿Y si pensamos en una escritura disidente, que irrumpa para crear hendijas por las que se cuelen registros del lenguaje que circula vivo, por fuera de la academia? ¿Y si hablamos de escrituras académicas en plural? Escrituras académicas otras. Hablemos de la creación de textos contaminados de proceso, contaminados de vida.

Propongo una escritura académica que se muestre atravesada por la experiencia, para volverse performativamente experiencial. No experimental, sino experiencial. Como dice Larrosa (2006, p. 472), conviene “[...] separar claramente experiencia de experimento, en descontaminar la palabra experiencia de sus connotaciones empíricas y experimentales. Se trata de no hacer de la experiencia una cosa, de no objetivarla, no cosificarla, no homogeneizarla, no calcularla, no hacerla previsible".

Abordar la escritura académica desde la experiencia supone entender esta última no "[...] como lo que es sino como lo que acontece, no desde una ontología del ser sino desde una lógica del acontecimiento, desde un logos del acontecimiento" (LARROSA, 2006, p. 473). Y es precisamente en la escritura como la entiendo aquí que el conocimiento acontece. Multiplicar los modos de escribir supone indiscutiblemente multiplicar el potencial de sentido, dar lugar a nuevos conocimientos que no se darían de otra manera.

Hablemos también de otros lenguajes no verbales, emancipados de la tiranía lingüística, para que entablen juegos de seducción con las palabras. Hablemos de romper el modelo ceñido de pretendida erudición que se inserta en la obsolescencia de los valores científicos decimonónicos y de entronización de las ciencias duras, la vara positivista con la que aún hoy se mide la calidad de la producción académica en las humanidades. Descontextualizar, desnaturalizar, deconstruir, dislocar, para permitir que se produzcan nuevas asociaciones, nuevos inventos. Una escritura académica transgénero, contra-academicista, multirrecursos. Propongo aquí desplazamientos genéricos, mecanismos de des/re/apropiación discursiva, de montaje, de collage, para que el tejido discursivo ofrecido no repela ni esconda el proceso, sino que opere como un remolino, atrayendo cuanto recurso parezca conveniente, mostrando las costuras por las que se filtren nuevas ideas. Sugiero un decir-mostrar que enriquezca y multiplique la creación de sentido.

Uno de los supuestos que aún actualmente subyacen al conjunto de convenciones de la escritura académica tradicional es concebir a las palabras tipeadas en la página como vehículos transparentes de las ideas que comunican. La tipografía debe volverse invisible para que el ojo lector pueda concentrarse de lleno en los conceptos vertidos, igual que una copa de cristal permite apreciar el vino que contiene, tal como lo decía la famosa tipógrafa Beatrice Warde en los años treinta. Sin embargo, la tipografía nunca es transparente. La elección de determinada tipografía como aceptable y otra como inadmisible en contextos específicos tiene su explicación en la historia y los contextos en donde se gestaron, en una combinación de factores sociales, culturales, económicos, tecnológicos, estéticos y comerciales. Es sólo que hemos sido entrenadas para naturalizarla. Así como la objetividad y la neutralidad son cuidadosamente construidas con sofisticadas movidas discursivas que aprendemos como escritoras en la academia para posicionarnos en la disciplina y sonar convincentes, también nos han enseñado a no ver algo tan evidente como el tipo de letra sin la cual no sería posible lectura alguna. Pensemos rápidamente cómo cambiaríamos nuestra percepción de lo mismo que estamos leyendo en este momento si se encontrara escrito en letra gótica o Comic Sans, o si se hubieran utilizado distintos tamaños de tipografía y mayúsculas estratégicamente. Lo que planteo es aprovechar la opacidad tipográfica a nuestro favor, metadiscursivamente, en pos de una escritura performativa, en el sentido más

${ }^{6}$ El título de su influyente colección de ensayos sobre tipografía The Crystal Goblet (La Copa de Cristal), aludía justamente de manera metafórica a la transparencia a la que debía aspirar la tipografía. 
básico del término. Se puede aludir a contextos y traer a la mente del ojo lector un sinfín de nociones a través de la importación discursiva en términos de Nørgaard (2009), provocada por el mero optar por un determinado tipo y tamaño de letra. Se puede decir mejor lo que se escribe si se piensa cuidadosamente con qué se escribe, y cómo se escribe, literalmente. O mejor, se pueden decir más cosas, otras cosas. La lectura mecanizada de izquierda a derecha y de arriba hacia abajo, heredada gracias a siglos del reinado del formato códice, también contribuye a la naturalización de la idea (obvia ilusión) de que la ciencia progresa linealmente, sin sobresaltos ni cambios de rumbo, y se desarrolla de la misma manera con que la comunidad académica comunica sus resultados y avances ${ }^{7}$. Hablemos también con los espacios en blanco, y la posición estratégica de determinadas partes del texto en la página en combinación o yuxtaposición con otras. Para que el decir, al ser meta-reflexivo, sea más coherente con los procesos que en la realidad atravesamos. Como bien dicen Baldry y Thibault (2005, p. 58), la página, que solía ser "[...] una unidad lingüística cien años atrás, se ha vuelto hoy ante todo una unidad visual" (nuestra traducción). Definitivamente, sostengo que el espacio también puede ser una arena semiótica invaluable.

\section{Lo que podemos aprender de la ficción multimodal}

A diferencia del mundo académico, en la literatura la experimentación tipográfica y la disrupción del diseño convencional de la página lleva siglos de historia, y atraviesa hoy un boom innegable (HALLET, 2018; NØRGAARD, 2019). Para abordar este creciente fenómeno literario ficcional en el siglo XXI, han surgido categorías como novela multimodal (HALLET, 2009; MAZIARCZYK, 2011, 2012; GIBBONS, 2012, 2015), novela visual o novela bíbrida (LUKE, 2013; SADOKIERSKI, 2010), narrativas mutantes (IACOB, POSADA, 2018) o textovisuales (MORA, 2019), para referirse a aquella ficción literaria en formato códice que se construye con diversos recursos semióticos: desde el uso estratégico de la tipografía y el espacio de la página hasta dibujos, fotos y gráficos que no se corresponden con la noción de ilustración tradicional, sino que son parte inseparable de la narrativa, con funciones determinadas en su aporte de sentido a la obra en sus múltiples combinaciones. Con frecuencia, estas ficciones integran al texto facsímiles de memorabilia o documentos de la vida cotidiana, como etiquetas, recortes de diario, folletos, o tickets?. Otras veces, toman por completo la forma de géneros discursivos no asociados convencionalmente a la ficción, como un diccionario, un catálogo, o géneros virtuales como mails o chats $^{10}$, operando éstos a la manera de restricción oulipiana, y produciendo un efecto indicial de proceso y de autenticidad, de borramiento del límite entre ficción y realidad, literatura y vida cotidiana. (MUSSETTA, 2020).

Estas novelas nos invitan a explorar cómo cada recurso semiótico puede contribuir a construir sentido en combinación con otros, y, debido a que la ficción es escritura creativa por naturaleza, justamente es allí donde se encuentran innumerables posibilidades de aprovechamientos novedosos de tales recursos: “[...] cada ficción es única en su manifestación de multimodalidad" (GIBBONS, 2012, p. 3).

\footnotetext{
7 Por cierto, las palabras no son inocentes: como académicas nos vemos forzadas a informar resultados (minimizando los procesos), y a comunicar avances (a menudo ignorando y ocultando las idas y vueltas propias del quehacer investigativo). Me pregunto cuánto más podría avanzar una línea de investigación si se compartieran los desaciertos, los aparentes callejones sin salida, para abrir el juego a otras colegas que propongan nuevos caminos a partir de los errores o supuestos intentos fallidos de respuesta a un problema.

8 A linguistic unit 100 years ago has now become primarily a visual unit.

9 Por ejemplo, la novela de Caroline Preston, The Scrapbook of Frankie Pratt: A novel (2011), o la de Graham Rawle, Diary of an Amateur Photographer (1998).

10 Ver por ejemplo, Lovers' Dictionary (2011), de David Levithan, o Mis Whatsapp con Mamá (2014), de Alban Orsini.
}

Revista Teias v. 21 • n. 63• out./dez. 2020 • Seção Temática Docência, currículo, didática, aula: fantástico arquivo político da diferença 
[...] la novela multimodal es sólo un ejemplo de la multimodalidad como práctica cultural general de significar, dar sentido al mundo y comunicar. Sin embargo, debido a la especificidad de su ocurrencia en un texto literario, la multimodalidad en la novela no sólo refleja o imita las prácticas sociales y culturales semióticas en forma ficcional; también las refleja y comenta de manera crítica o autorreflexiva. (HALLET 2018, p. 36-37, nuestra traducción) ${ }^{11}$

De allí que el estudio del potencial de esta clase de ficción de tematizar y cuestionar su propia capacidad representativa o de asegurar confiabilidad puede volverse un valioso aporte para luego explorar nuevas formas multimodales posibles en escrituras académicas disidentes.

\section{Algunos ejemplos de escritura académica multimodal ${ }^{12}$}

La semiótica social multimodal (KRESS, VAN LEEUWEN, 2006), que vincula lo representacional con lo social, afirma un cambio de énfasis del lenguaje a otros sistemas semióticos. Con el foco en el diseño visual, propone examinar los textos en relación con una red de opciones socialmente creada que posee potencial de sentido, el que se realiza en el contexto de uso. Desde esta perspectiva, este enfoque parte del principio de que los modos de comunicación ofrecen opciones específicas compartidas cultural y socialmente (recursos semióticos), las que nunca son rígidas ni estáticas sino que se encuentran por ende en un proceso de constante flujo y transformación.

Contra viento y marea, hay esfuerzos de comunicación y publicación académica que se toman el desafío multimodal muy seriamente. La InSEA (International Society for Education Through $A r t$ ), por ejemplo, una organización asociada a la UNESCO, alienta proyectos editoriales en este sentido $^{13}$, entre los que se encuentran IJEA (International Journal of Education Through Art), y la revista $I M A G$, ambas publicaciones en línea, de revisión por pares y de acceso abierto, para la identificación, publicación y difusión de teorías y prácticas de educación artística a través de métodos y medios visuales. En ambos casos se admiten, además de artículos convencionales, ensayos visuales que gozan "[...] el mismo estatus académico que los artículos tradicionales basados en texto"14, y por los que se entienden, según sus propias pautas de presentación de propuestas,

[...] presentaciones basadas en imágenes/texto, [que] deben integrar la imagen y el texto de manera creativa para documentar, evaluar o reflexionar sobre las actividades, eventos o resultados del aprendizaje basado en el arte. Piensen en ello como una exploración de un tema que transmite ideas y significado a través de medios visuales así como del lenguaje [...]. Las imágenes no deben

\footnotetext{
11 [...] the multimodal novel is just one instance of multimodality as a general cultural practice of signifying, making sense of the world and communicating. However, due to the specificity of occurring in a literary text, multimodality in the novel does not simply mirror or imitate semiotic social and cultural practices in fictional form; it also reflects and comments upon them critically or self-reflexively.

12 Debido a mi inspiración en y referencia a la ficción multimodal en formato códice, las nociones de escritura multimodal a la que responden los ejemplos que doy aquí responden en mayor o menor medida a documentos enmarcados en la lógica de la sucesión de páginas. Sin embargo, no desconozco y celebro la irrupción de otras iniciativas de comunicación académica, como las de carácter audiovisual: las publicaciones científicas que admiten contribuciones en forma de video ensayos o video abstracts, por ejemplo.

${ }_{13}$ Algunas de ellas, disponibles aquí: https://www.insea.org/our-publications.

14 We view visual essays as equal in academic status to traditional text based articles.
} 
simplemente ilustrar el texto [...] sino que deben constituir un componente esencial en la articulación de significado. (Nuestra traducción) ${ }^{15}$

Es importante destacar que este tipo de escritura académica no es exclusiva del género ensayo, ni es necesario investigar en el campo de las disciplinas artísticas para ponerla en práctica. Nick Sousanis, por ejemplo, se atrevió en 2015 a redactar su propia tesis doctoral íntegramente en formato cómic: Unflattening ${ }^{16}$, un texto anfibio, tal como él lo llama, combinando imagen y texto para explorar performativamente la relación entre conocimiento, percepción, visualidad, y lenguaje, y combinando nociones del campo de la filosofía, las artes, las teorías de la cognición, la mitología y la literatura (Figura 1$)^{17}$.

Figura 1: Reflexión anfibia en la tesis de Sousanis sobre el modo verbal y no verbal

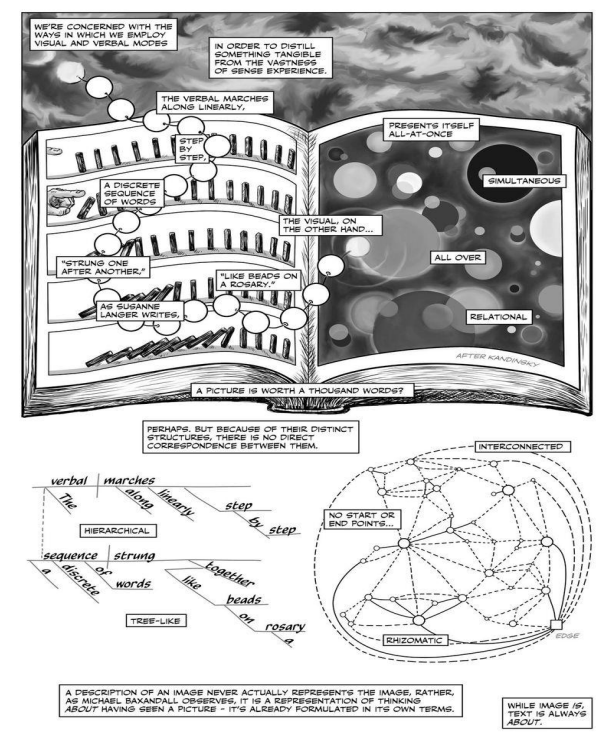

Fuente: SOUSANIS, Nick. Unflattering, 2015, p. 58.

\footnotetext{
15 Visual essays or image/text-based submissions, [which] should integrate image and text in a creative way to document, evaluate or reflect on art-based learning activities, events or outcomes. Think of it as an exploration of a topic that conveys ideas and meaning through visual means as well as language [...] Images should not simply illustrate the text [...] but should constitute an essential component in the articulation of meaning.

Las pautas editoriales de donde se extrajeron las citas se encuentran disponibles en https://www.insea.org/sites/default/files/photoessay CFP.pdf.

${ }_{16}$ El título, de difícil traducción (en español sería algo así como proceso de desachatamiento), alude al mundo Flatland (Tierra Chata o Chatalandia) de la homónima novela de Edwin A. Abbott, donde sus habitantes bidimensionales son incapaces de comprender el concepto de "hacia arriba". Sousanis nos exhorta con su trabajo a no parecernos a ellos, e intentar ver más allá de los límites de nuestros mecanismos usuales de pensamiento, para ganar nuevos, diversos, y combinados puntos de vista que habiliten nuevas formas de "ver/conocer".

17 De hecho, desde hace unos años mantiene una página web en constante crecimiento, donde registra y compila iniciativas propias y ajenas de lo que él denomina "alternative scholarship" (trabajos académicos alternativos): http://spinweaveandcut.com/comics-alternative-scholarship/.
} 
Por su parte, en el campo de las teorías transmedia, Carlos Scolari y Fernando Rapa han publicado recientemente el libro Media Evolution, que propone una reflexión sobre el desarrollo de los ecosistemas mediáticos a partir de una combinación inseparable de conceptos, citas e imágenes (Figura 2). Según sus propias palabras:

Cada vez me siento menos cómodo en la escritura científica tradicional. Más que incómodo, me siento insatisfecho: el sistema académico, al centrarse en los artículos y libros científicos, no valora la producción de textos creativos, en formatos innovadores y que realmente hagan pensar al lector más allá de sus palabras. Si bien no pienso dejar de publicar textos científicos en los canales habituales, me interesa explorar nuevas formas de expresión y formatos editoriales (Scolari, 2019).

Figura 2: Combinación de imagen y texto en doble página del libro Media Evolution ${ }^{18}$
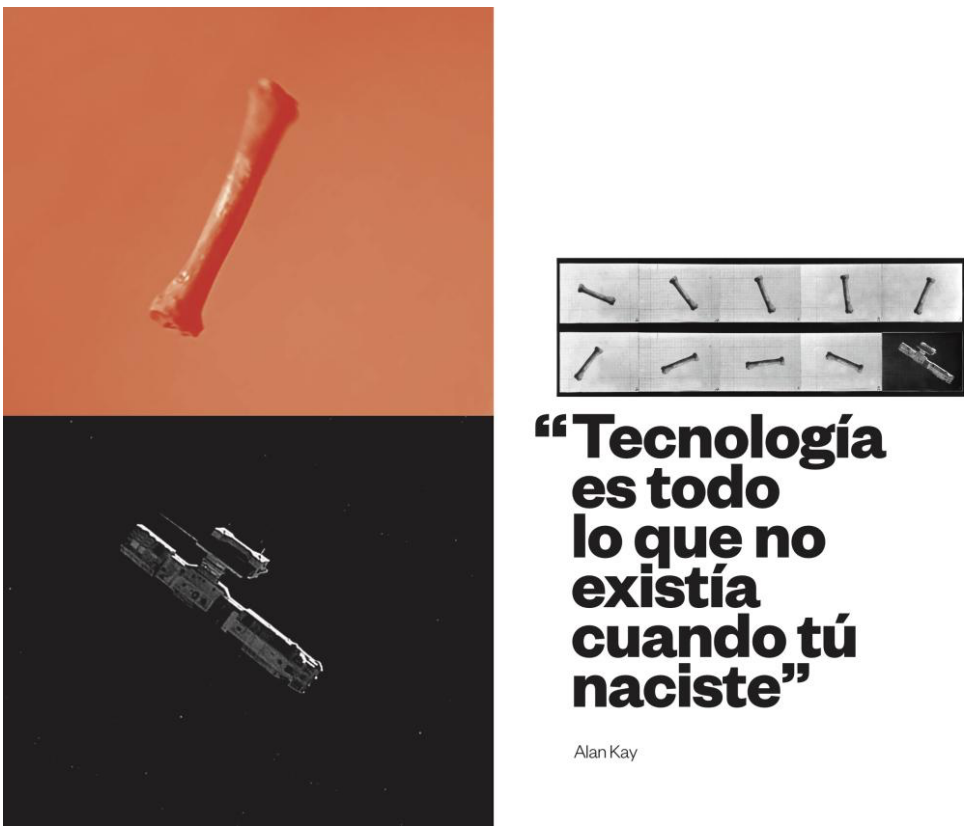

‘Tecnología es todo lo que no existia cuando tú naciste"

AlanKay

Fuente: SCOLARI, Carlos; RAPA, Carlos. Media Evolution. Sobre el origen de las especies mediáticas, 2019b. p. 20-21.

Es en este sentido que aliento a esbozar los primeros pasos hacia una escritura académica textovisual, multimodal: es decir, a explorar formas en que los géneros académicos puedan de a poco ir desplazando la primacía del recurso lingüístico para dar lugar a textos más abiertamente visuales y creativos, que conjuguen diversos recursos semióticos, y puedan así enriquecer nuevas formas del decir, complejizando las formas de comunicación académica al apelar al desarrollo textual no lineal además del lineal, y tensionando imagen y texto en sus infinitas posibilidades de crear sentido. En palabras de Sousanis (2018, p. 158), tratar de "[...] combinar el diverso rango de maneras de realizar significado para desarrollar su potencial multiplicativo".

\footnotetext{
18 A propósito de esta página, Scolari (2019) comenta que la frase de Alan Kay “[...] también nos permitió jugar con la elipsis más famosa de la historia del cine (el fémur que se transforma en nave espacial en 2001 de Stanley Kubrick ) y traducirla en el formato de los primeros estudios sobre el movimiento de Eadweard Muybridge a finales del siglo XIX. O sea, en una misma página pusimos a dialogar a Alan Kay, Stanley Kubrick y Eadweard Muybridge".
} 
La cuestión de la legitimación de las escrituras académicas disidentes

El llamado es a trabajar con el cruce de dimensiones tradicionalmente consideradas opuestas, con la consecuente problematización de los límites de categorías supuestamente discretas, tales como escritura académica/escritura creativa, escritura ficcional/no ficcional, escritura narrativa/argumentativa, escritura como proceso/escritura como producto, discursos verbales/no verbales, lectura lineal/no lineal, teoría/práctica, autor/lector/crítico/diseñador, y creación/reflexión sobre la acción, ya que se insiste en un fuerte componente meta-reflexivo. Se trata de escrituras de carácter "[...] recursivo, no lineal, anti teleológico, operando a través de metodologías emergentes que se diseñan caso a caso, trabajando sobre las particularidades, y cuestionando las jerarquías de los saberes heredados del positivismo" (GRASS KLEINER, 2019). De hecho, y siguiendo a Contreras (citado en GRASS KLEINER, 2019), la naturaleza de este tipo de procedimientos se vuelve intrínsecamente contrahegemónica, frente a un mercado del conocimiento globalizado que opera desde la estandarización y la homogeneización de todas las disciplinas bajo el modelo de las ciencias duras.

Hace rato que la tecnología ofrece las herramientas necesarias para desarrollar, compilar y publicar este tipo de escritura. Es evidente que los obstáculos no son técnicos sino ideológicos. Ahora bien, ante este panorama, ¿cómo hacer para no pecar de ingenuos idealistas y tener chances de que este tipo de prácticas escriturales obtengan reconocimiento en la academia? ¿Cómo evitar que la apertura a otros lenguajes, géneros y recursos haga que virtualmente cualquier texto devenga en escrituras académicas disidentes? Hay varias cuestiones cruciales que deberán considerarse, y estimo que allí radica el gran desafío hacia adelante. Entre muchos otros aspectos que convendrá dilucidar de a poco, y que por supuesto ameritará trabajos futuros, señalo aquí el referido a la comunicabilidad, la visibilidad, y a la calidad académica. Es allí donde se presenta el reto de, sin renunciar al potencial creativo que nos hemos propuesto, encontrar junto al dispositivo elegido los marcadores de legitimación académica estratégicos (como el proceso de revisión ciega de pares, las referencias bibliográficas de rigor, la identificación DOI o la indización de las publicaciones, por ejemplo) que permitan naturalizar su lugar en la comunidad académica. Mientras tanto, puedo usar la creatividad para sortear las limitaciones que nos impone la academia para publicar, e incluir imágenes que cuenten a modo de pequeña muestra lo que espero pueda aparecer como texto principal en algún momento (Figura 4). Sigamos pensando alternativas, sigamos creando vínculos, sigamos creando.

Figura 3: Fragmento de un texto académico disidente sobre escrituras académicas disidentes

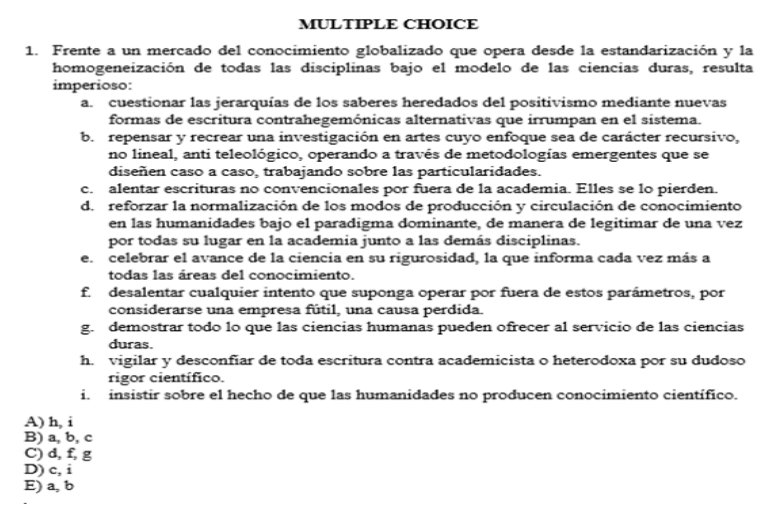

Fuente: MUSSETTA, Mariana; SIRAGUSA, Cristina; VOTTERO, Beatriz. Simposio. Escrituras en artes: registros y reflexividades. (2020) p. 58. 


\section{REFERENCIAS}

BALDRY, Anthony; THIBAULT, Paul J. Multimodal transcription and text analysis. London: Equinox Pub, 2006.

BLANCA, Philippe. The scientific journal in the age of digital multimodality. 285. Doctoral dissertation, Docteur de l'université du Luxembourg en Sciences de l'Éducation. University of Luxembourg. Luxemburgo, 2014.

BORGES, Jorge Luis. Obras completas. Buenos Aires: Emecé Editores, 1984.

CAMPOS, Haroldo. Paul Valéry e a poética da tradução: as formulações radicais do célebre poeta francês a respeito do ato de traduzir. In: TÁPIA, Marcelo; NÓBREGA, Thelma Médici (orgs.). Haroldo de Campos - Transcriação. São Paulo: Perspectiva, 2013b, p. 61-75.

CAMPOS, Haroldo. Tradição, Transcriação, Transculturação. In: TÁPIA, Marcelo; NÓBREGA, Thelma Médici (orgs.). Haroldo de Campos - Transcriação. São Paulo: Perspectiva, 2013a, p. 197205.

CORAZZA. Sandra. O que se transcria em educação? Porto Alegre: UFRGS; Doisa, 2013.

CORAZZA. Sandra. Os cantos de Fouror. escrileitura em Filosofia-educação. Porto Alegre: Sulina, 2008.

GIBBONS, Alison. Creativity and multimodal literature. In: JONES, Rodney (ed.). The Routledge handbook of language and creativity. London: Routledge, 2015. p. 315-328.

GIBBONS, Alison. Multimodal literature and experimentation. In: BRAY, Joe et al (eds.). The Routledge companion to experimental literature. New York: Routledge, 2012. p. 420-434.

HALLET, Wolfgang. The multimodal novel: the integration of modes and media in novelistic narration. In: HEINEN, Sandra; SOMMER, Roy (eds.) Narratology in the Age of Cross-Disciplinary Narrative Research. New York: Walter de Gruyter, 2009. p. 129-153.

HALLET, Wolfgang. Reading multimodal fiction: a methodological approach. Anglistik: International Journal of English Studies, Berlin, v. 29, n. 1, p. 25-40, march 2018.

IACOB, Mihai; POSADA Adolfo R. (eds.). Narrativas mutantes: anomalía viral en los genes de la ficción. Bucarest: Editura Ars Docendi - Universitatea din, 2018.

KRESS, Gunther; VAN LEEWUEN, Theo Van. Reading images: the grammar of visual design. London: Routledge, 2006.

LARROSA, Jorge. Algunas notas sobre la experiencia y sus lenguajes. Estudios filosóficos, Madrid, v. 55, n. 160, p. 467-480, 2006.

LUKE, Jarid. Writing the visible page: a multimodal approach to graphic devices in literary fiction. 202. Doctoral dissertation, Creative Writing and Literary Studies. Queensland, Queensland University of Technology, 2013.

MAZIARCZYK, Grzegorz. Print strikes back: typographic experimentation in contemporary fiction. In: WOOLF, Werner (ed.). The metareferential turn in contemporary arts and media: forms, functions, attempts at explanation. Amsterdam: Rodopi, 2011. p. 169-193.

MAZIARCZYK, Grzegorz. Towards multimodal narratology. Interfaces: Image, Texte, Language, Massachusetts, v. 32, n. 2, p. 111-125, 2012. 
MORA, Vicente Luis. Entre estética y literatura: metodologías para leer el continuo textovisual de las obras literarias en la era digital. ACTIO NOV A Revista de Teoría de la Literatura y Literatura Comparada, Madrid, v. 3, n. 2, p. 456-480, dic. 2019.

MUSSETTA, Mariana. En busca de lo real y lo auténtico: experimentación gráfica en nuevas narrativas del Siglo XXI. Hyperborea. Revista de ensayo y creación. Laboratorio Texto, imagen y sociedad [LabTIS], Bariloche, Universidad Nacional de Río Negro, v. 3, p. 53-70, nov. 2020.

MUSSETTA, Mariana; SIRAGUSA, Cristina; VOTTERO, Beatriz. Simposio Escrituras en artes: registros y reflexividades. In: SIRAGUSA, Cristina; REYES, Manuela (ed.). Libro de Actas III Jornada de Investigación en Artes UNVM. Villa María: Universidad Nacional de Villa María, 2020, p. 37-66.

NØRGAARD, Nina. The semiotics of typography in literary texts. A multimodal approach. Orbis litterarum, Odense, v. 64, n. 2, p. 141-160, march 2009.

NØRGAARD, Nina. Multimodal stylistics of the novel: more than words. New York: Routledge, 2018.

PIGLIA, Ricardo. Crítica y ficción. Barcelona: Debolsillo, 2017.

PRIETO, Julio. Todo lo que siempre quiso saber sobre la autoficción y nunca se atrevió a preguntar (con una lectura de Mario Levrero). Revista de Crítica Literaria Latino Americana, LimaBoston, Año XLV, n. 90, p. 219-242, 2019.

ROCHA, Marcela Cristina de. Etnografemas: docências em criação. Dissertação (Mestrado), Programa de Pós-Graduação em Educação, Universidade Federal do Rio Grande do Sul, Faculdade de Educação, Porto Alegre, 2019.

SADOKIERSKI, Zoe. Visual writing: a critique of graphic devices in hybrid novels, from a visual communication design perspective. Doctoral Thesis. Doctor of Philosophy in Design. University of Technology, Sydney, 2010.

SAER, Juan José. El concepto de ficción. Buenos Aires: Seix Barral, 2014.

SCOLARI, Carlos. Media evolution: algo más que un libro... Hipermediaciones.com. 6 ago. 2019. Disponible en https://hipermediaciones.com/2019/08/06/media-evolution-algo-mas-que-unlibro. Acceso en 10 ago. 2020.

SCOLARI, Carlos; RAPA, Fernando. Media evolution. Sobre el origen de las especies mediáticas. Buenos Aires: La marca Editora, 2019.

SOUSANIS, Nick. Unflattening. Cambridge: Harvard University Press, 2015.

SOUSANIS, Nick. Frames of thought. PMLA, New York, v. 133, n. 1, p. 154-159, jan. 2018.

VALÉRY, Paul. Monsieur Teste. Paris: Gallimard, 1946.

VALÉRY, Paul. Traduction en vers des Bucoliques de Virgiles. (précédé de Variations sur Bucoliques) Paris: Gallimard, 1956.

VALÉRY, Paul. Variedades. Traducción João Alexandre Barbosa. São Paulo: Iluminuras, 1991.

VALÉRY, Paul. Variété III, IV et V. Paris: Gallimard, 2002.

WARDE, Beatrice. The crystal goblet: sixteen essays on typography. London: World Publishing Company, 1954. 
Informações do(a)(s) autor(a)(es)

Máximo Daniel Lamela Adó

Professor na Faculdade de Educação e no Programa de Pós-Graduação em Educação da Universidade Federal do Rio Grande do Sul - UFRGS

E-mail:maximo.lamela@ufrgs.br

ORCID: https://orcid.org/0000-0002-7643-1785

Link Lattes: http://lattes.cnpq.br/5778480459612105

Mariana Mussetta

Universidad Nacional de Villa María (UNVM)

E-mail:mmussetta@unvm.edu.ar

ORCID: https://orcid.org/0000-0002-6476-6924

Link Lattes: http://lattes.cnpq.br/5845916499753634 